\title{
Influence of Collateral Flow Reduction on Electrophysiologic Properties of Preexisting Ischemic Area and Inducibility of Ventricular Arrhythmias in the Dog
}

\author{
Katsusuke Yano, M.D., Masanobu Hirata, M.D., \\ Yoriaki Matsumoto, M.D., Mitsuhiro Mori, M.D., \\ Osamu Hano, M.D., Rafique Ahmed, M.D., \\ Takao Mrsuoka, M.D., and Kunitake Hashiba, M.D.
}

\section{SUMmaRY}

Electrophysiologic properties of the left ventricle, vulnerability to ventricular arrhythmias and regional myocardial blood flow (RMBF) of the left ventricle were examined during superposition of acute ischemia on a healed myocardial infarction. The left circumflex coronary artery (LGX) was ligated in 13 dogs with a 28-day-old anteroapical infarction. Six $(46 \%)$ of 13 dogs had reproducible ventricular tachycardia in response to programmed ventricular stimulation before LCX ligation. Ventricular fibrillation could be induced in 2 of these 6 dogs. After LCX ligation, $11(85 \%)$ of 13 dogs had ventricular arrhythmias induced by ventricular stimulation. Nine of 13 dogs had ventricular tachycardia and 7 of 13 dogs had ventricular fibrillation. The heterogeneity of the effective refractory period ( $J \mathrm{ERP}$ ) and the local intraventricular conduction time (LIVCT) in the border and the infarct zones of the left ventricle increased significantly after LCX ligation. RMBF in the border and the infarct zones were markedly decreased by LCX ligation. The magnitude of reduction of $\mathrm{RMBF}$ was correlated significantly with the prolongation of LIVGT. In conclusion, acute critical reduction of the collateral blood supply causes a more heterogeneous refractory period and conduction delay in the preexisting ischemic area of the heart, increasing the vulnerability to lethal ventricular arrhythmias.

\section{Additional Indexing Words:}

Ventricular arrhythmia

Programmed ventricular stimulation Regional myocardial blood flow Myocardial infarction Acute myocardial ischemia

\footnotetext{
From the Third Department of Internal Medicine, Nagasaki University School of Medicine, Nagasaki.

Address for reprint: Katsusuke Yano, M.D., Third Department of Internal Medicine, Nagasaki University School of Medicine, 7-1 Sakamoto-cho, Nagasaki-shi 852, Japan.

Received for publication March 23, 1987.
} 
QUDDEN cardiac death from ventricular arrhythmias is a serious clinical 1 manifestation of a healed myocardial infarction. The recurrence of lifethreatening ventricular arrhythmias has been well documented in patients with multivessel coronary artery disease and a previous myocardial infarction. ${ }^{1,21}$ However, the electrophysiologic relationship between this combination of acute ischemia and healed myocardial infarction and the occurrence of life-threatening ventricular arrhythmias has not been defined. Several investigators have performed electrophysiologic studies of ventricular arrhythmias resulting from acute ischemia superimposed on preexisting ischemia. ${ }^{3)-51}$ In these studies, however, the relationship between changes in clectrophysiologic properties and the magnitude of reduction of collateral blood supply to the preexisting ischemic area has not been examined. The present investigation was designed to examine the relationships between the induction of ventricular arrhythmias and changes in both electrophysiologic properties and regional myocardial blood flow (RMBF) of the left ventricle when acute ischemia is superimposed on a healed myocardial infarction in the dog.

\section{Methods}

Thirteen mongrel dogs of either sex weighing 9 to $12 \mathrm{~kg}$ were anesthetized intravenously with sodium pentobarbital $(25 \mathrm{mg} / \mathrm{kg})$ and ventilated with room air through a tracheal tube using a Harvard respirator. A left thoracotomy was performed at the fifth intercostal space under aseptic conditions. The heart was exposed and suspended in a pericardial cradle. An anteroapical myocardial infarction was created by ligation of the left anterior descending coronary artery (LAD) just proximal to the first diagonal branch, as shown in Fig. 1. The chest was closed $60 \mathrm{~min}$ later and the dogs were allowed to recover.

An average of $28 \pm 6$ days after the initial surgery, the dogs were anesthetized with sodium pentobarbital $(25 \mathrm{mg} / \mathrm{kg})$ and ventilated with room air through a tracheal tube using a Harvard respirator. The heart was approached by a median sternotomy. Systemic arterial pressure was measured with a catheter introduced into a femoral artery. Pressure measurements were obtained with a Statham P32Db pressure transducer and displayed on an oscillograph (Fukuda Denshi, Monitorscope CS-800). The left circumflex coronary artery (LCX) was ligated distal to the first marginal branch to superimpose acute ischemia on the healed myocardial infarction (Fig. 1).

Programmed ventricular stimulation and measurement of regional myocardial blood flow (RMBF) of the left ventricle were performed immediately before and $30 \mathrm{~min}$ after LCX ligation. Teflon-coated stainless steel bipolar 


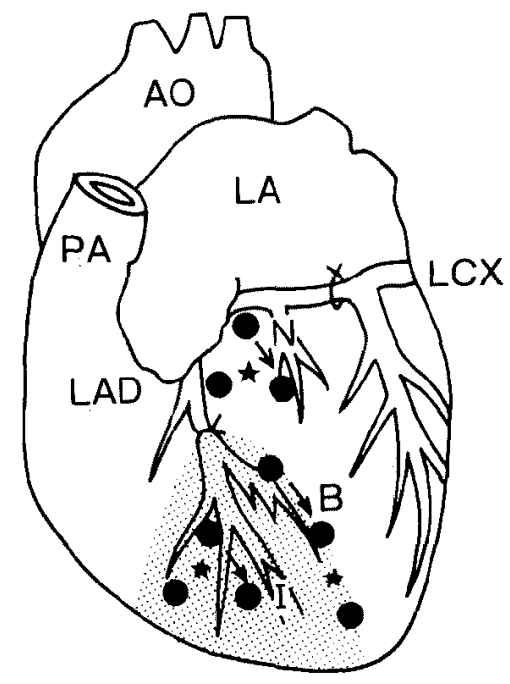

Fig. 1. Schematic representation of the experimental preparation Glosed circles slow the position of bipolar electrodes for recording endocardial electrograms and for electrical stimulation of the ventricle. Stars show the points for measurement of regional myocardial blood flow (RMBF). The local intraventricular conduction time (LIVCT) was measured as the conduction time between 2 pairs of electrodes indicated by arrows. $\mathrm{AO}=$ aorta; $\mathrm{PA}=$ pulmonary artery; $\mathrm{LA}=$ left atrium; $\mathrm{LAD}=$ left anterior descending coronary artery; $\mathrm{LCX}=$ left circumflex coronary artery; $\mathrm{N}=$ normal zone; $\mathrm{B}=$ border zone; $\mathrm{I}=$ infarct zone.

wires $(0.15 \mathrm{~mm}$ in diameter $)$ were used to record electrical activity of the left ventricular endocardium and to stimulate multiple sites of the left ventricular endocardium. The teflon coat was removed from the tip of the wires to expose approximately $2 \mathrm{~mm}$ at the tip of each wire. Nine pairs of the bipolar electrodes were positioned in the endocardium of the left ventricle with 22 gauge hypodermic needles. The intertip interval of each bipolar pair was $2 \mathrm{~mm}$. As shown in Fig. 1, 3 pairs of bipolar electrodes were positioncd in the normal zone of the left ventricle, 3 pairs in the anteroapical infarct zone and the remaining 3 pairs in the border zone around the infarct zone. These bipolar electrodes were separated by approximately $1.5 \mathrm{~cm}$ and the exact positions were confirmed by postmortem examination after completion of the experimental procedures. The bipolar electrodes were connected through a switch box to a programmable electrical stimulator (Fukuda Denshi, Cardiac Stimulator BC-02A), an oscillograph (Fukuda Denshi, Monitorscope CS-800) and a multichannel recorder (Siemens, Mingograf 800). The surface electrocardiograms and local endocardial electrograms were recorded simultaneously. The input from the bipolar electrodes was connected to an amplifier and filtered at 30 
to $500 \mathrm{~Hz}$. The electrocardiographic data were stored on an FM magnetic tape (SONY, Instrumentation Tape Recorder UN6930) for later retrieval and analysis and were also recorded at a paper speed of 100 or $250 \mathrm{~mm} / \mathrm{sec}$ with identical gain settings. Electrical stimulation at each site of the left ventricle was made with a 2-msec duration rectangular pulse and stimulus strength was kept at twice the diastolic threshold throughout the electrophysiologic study.

Programmed ventricular stimulation was applied through all bipolar electrode pairs for induction of ventricular arrhythmias. Premature ventricular stimuli of increasing prematurity (S2) were given after a ventricular pacing of 8 beats ( $\mathrm{S} 1$ ) at a cycle length of $300 \mathrm{msec}$, until the stimulus failed to capture the ventricle. Then, a second ventricular premature stimulus (S3) was applied at varying $\mathrm{S} 1-\mathrm{S} 2$ intervals and the S2-S3 interval was progressively shortened in increments of $10 \mathrm{msec}$ until S3 failed to capture the ventricle. After completion of this procedure, brief bursts ( 3 to 5 beats) of rapid ventricular pacing were performed through each electrode pair. Rapid ventricular pacing from each site of the left ventricle was performed at cycle lengths that were shortened in $10 \mathrm{msec}$ increments until the stimuli failed to achieve $1: 1$ ventricular capture, or until ventricular tachycardia or fibrillation occurred. If ventricular stimulation from one site of the left ventricle induced ventricular tachycardia, the identical mode of ventricular stimulation from the same site was repeated. Electrically-induced sustained ventricular tachycardia was terminated with brief bursts of rapid ventricular pacing. Direct current counter-shocks (10 to 20 joules) were applied to the epicardium to terminate ventricular fibrillation by using a defibrillator (Nihon Kohden, TEC-5100).

Nonsustained ventricular tachycardia was defined as 5 or more successive ventricular beats that reverted spontaneously to normal sinus rhythm in less than $10 \mathrm{sec}$. Sustained ventricular tachycardia, on the other hand, was considered as a run of ventricular tachycardia that lasted for $10 \mathrm{sec}$ or more and did not terminate spontaneously. Finally, ventricular fibrillation was defined as a ventricular arrhythmia with a nonuniform morphology and extremely short and variable cycle length.

The effective refractory period (ERP) of the sites in the normal, the border and the infarct zones of the left ventricle were determined by the introduction of progressively premature ventricular stimuli, after 8 paced beats at a fixed cycle length of $300 \mathrm{msec}$. The effective refractory period (ERP) was defined as the longest S1-S2 interval at which $\mathrm{S} 2$ failed to evoke a ventricular response. The heterogeneity of effective refractory period ( $\triangle \mathrm{ERP}$ ) in the 3 zones of the left ventricle was determined as the difference between the longest and shortest effective refractory period in each zone.

The local intraventricular conduction time (LIVCT) in the normal, the 
border and the infarct zones of the left ventricle were determined by ventricular pacing. Brief ventricular pacing with a cycle length of $300 \mathrm{msec}$ was applied through a pair of bipolar electrodes positioned in each zone of the left ventricle. The local intraventricular conduction time (LIVCT) was defined as the conduction time in milliseconds between 2 pairs of electrodes. Local intraventricular conduction times were measured between the points shown by arrows in Fig. 1. It was assumed that local intraventricular conduction occurred along the shortest route between the stimulating and recording sites, although other pathways may exist. In case of a significant reduction in the amplitude of the electrogram in the infarct zone, we employed high gain settings for the determination of the onset of the electrogram.

Regional myocardial blood flow (RMBF) was measured in the normal, the border and the infarct zones of the left ventricle using the hydrogen gas clearance method. Epoxy resin coated platinum wire, $0.01 \mathrm{~mm}$ in diameter, was used for determination of regional myocardial blood flow (RMBF). The epoxy resin was removed at a site $3 \mathrm{~mm}$ from the tip of the wire, exposing a region approximately $0.5 \mathrm{~mm}$ in length. Wires were placed in one point of the endocardial side of the normal, the border and the infarct zones of the left ventricle as shown by stars in Fig. 1. The wires were placed with a 24 gauge hypodermic needle. A silver-silver chloride electrode was embedded in the subcutaneous tissue of the thorax as an indifferent electrode. These electrodes were connected to a tissue flow meter (Unique Medical, UH Meter Model MHG-D1). Hydrogen gas was administered through the tracheal tube at a constant rate of 1 liter $/ \mathrm{min}$ for $60 \mathrm{sec}$. The hydrogen clearance curve showed an exponential slope. The analysis for determination of regional myocardial blood flow (RMBF) is described in Fig. 2. Regional myocardial blood flow was calculated using the formula based upon Zierler's theoretical method. ${ }^{6}$ '

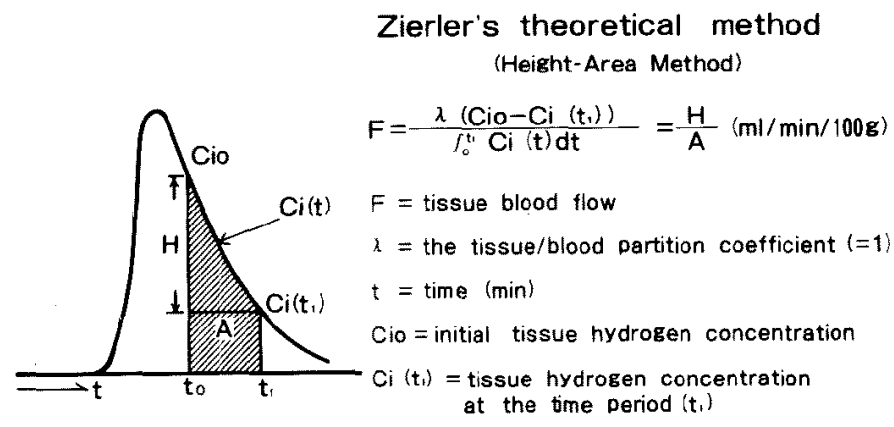

Fig. 2. Zierler's theoretical method (Height-Area Method) for measuring regional myocardial blood flow (RMBF). 
Data are presented as mean \pm SEM. Statistical analysis was performed by analysis of variance, two sided unpaired t-test and Chi-square test, as appropriate. Values were considered significant at the level of $\mathrm{p}<0.05$.

\section{Results}

All 13 dogs survived the experimental myocardial infarction without any postoperative complications and underwent the open chest electrophysiologic study and measurement of regional myocardial blood flow (RMBF) of the left ventricle. Stable hemodynamic conditions were observed at the time of experimental procedures in all dogs. The basal mean systemic arterial pressure was $94 \pm 8 \mathrm{mmHg}$ and the heart rate was $124 \pm 16$ beats $/ \mathrm{min}$.

At the beginning of the programmed ventricular stimulation, none of the 13 dogs manifested spontaneous ventricular arrhythmias. Results of electrical induction of ventricular arrhythmias are listed in Table I. Before LCX ligation, ventricular tachycardia was induced reproducibly in $6(46 \%)$ of the 13 dogs. Four of these 6 dogs had nonsustained ventricular tachycardia and

Table I. Regional Myocardial Blood Flow (RMBF)

\begin{tabular}{|c|c|c|c|c|c|c|}
\hline \multirow{4}{*}{ Dog } & \multicolumn{6}{|c|}{ Regional myocardial blood flow (RMBF) $\mathrm{ml} / \mathrm{min} / 100 \mathrm{~g}$} \\
\hline & & & \multicolumn{4}{|c|}{ Left ventricle } \\
\hline & \multicolumn{3}{|c|}{ Normal zone } & \multicolumn{3}{|c|}{ Border zone } \\
\hline & B & $A$ & \%change & B & A & $\%$ change \\
\hline 1 & 165 & 160 & 3 & 96 & 67 & 27 \\
\hline 2 & 156 & 138 & 5 & 90 & 80 & 11 \\
\hline 3 & 146 & 142 & 3 & 94 & 56 & 38 \\
\hline 4 & 164 & 160 & 2 & 82 & 32 & 61 \\
\hline 5 & 122 & 116 & 5 & 103 & 62 & 40 \\
\hline 6 & 128 & 124 & 3 & 92 & 34 & 63 \\
\hline 7 & 132 & 134 & 2 & 96 & 50 & 48 \\
\hline 8 & 124 & 122 & 2 & 84 & 41 & 51 \\
\hline 9 & 140 & 138 & 1 & 86 & 72 & 16 \\
\hline 10 & 174 & 184 & 5 & 64 & 38 & 41 \\
\hline 11 & 162 & 158 & 5 & 84 & 72 & 16 \\
\hline 12 & 168 & 170 & 1 & 78 & 54 & 31 \\
\hline 13 & 148 & 150 & 1 & 98 & 72 & 27 \\
\hline $\begin{array}{c}\text { mean } \\
\pm \\
\text { SEM }\end{array}$ & $\begin{array}{c}148.3 \\
\pm \\
18.2\end{array}$ & $\begin{array}{c}145.8 \\
\pm \\
19.3\end{array}$ & $\begin{array}{r}2.9 \\
\pm \quad 1.5\end{array}$ & $\begin{array}{l}88.2 \\
\pm \\
9.8\end{array}$ & $\begin{array}{l}51.2^{*} \\
\pm \\
15.5\end{array}$ & $\begin{array}{l}36.0^{* *} \\
\pm \\
16.3\end{array}$ \\
\hline
\end{tabular}

B, before LCX ligation, A, after LCX ligation.

$\%$ change = percent change of regional myocardial blood flow (RMBF); VA=ventricular arrhy- 
the other 2 had sustained ventricular tachycardia and ventricular fibrillation. After LCX ligation the incidence of electrically induced ventricular arrhythmias increased markedly, although none of the 13 dogs manifested spontaneous ventricular arrhythmias. Ventricular tachycardia and/or fibrillation could be induced in $11(85 \%)$ of the 13 dogs. Ventricular tachycardia was induced reproducibly in $9(69 \%)$ of the 13 dogs. Seven of these 9 dogs had nonsustained ventricular tachycardia. Ventricular fibrillation was induced in 7 of the 13 dogs; 5 of these 7 dogs also had electrically induced ventricular tachycardia.

The shortest and longest effective refractory periods and the heterogeneity of effective refractory period ( $\triangle \mathrm{ERP}$ ) in the 3 zones of the left ventricle are listed in Table II. Before LCX ligation, AERP in the normal zone had a value of $3.9 \pm 4.0 \mathrm{msec}$. By contrast, $\Delta \mathrm{ERP}$ was longer in the border and the infarct zones; $\Delta \mathrm{ERP}$ was $18.5 \pm 6.9 \mathrm{msec}$ with a range of 10 to $30 \mathrm{msec}$ in the infarct zone and $19.2 \pm 8.0 \mathrm{msec}$ with a range of 5 to $35 \mathrm{msec}$ in the border zone. After LCX ligation, the $\triangle \mathrm{ERP}$ was $4.6 \pm 3.1 \mathrm{msec}$ in the normal zone, which was not significantly different from the value before LCX liga-

and Electrically Induced Ventricular Arrhythmia

\begin{tabular}{|c|c|c|c|c|c|c|}
\hline & & f & \multicolumn{4}{|c|}{ Electrically induced $\mathrm{VA}$} \\
\hline \multicolumn{3}{|c|}{ Infarct zone } & \multicolumn{2}{|c|}{ VT } & \multicolumn{2}{|c|}{ VF } \\
\hline B & A & $\%$ change & B & A & $\mathrm{B}$ & A \\
\hline 75 & 36 & 52 & $(+)$ & $(+)$ & $(-)$ & $(-)$ \\
\hline 64 & 51 & 20 & $(-)$ & $(-)$ & $(-)$ & $(-)$ \\
\hline 72 & 46 & 36 & $(-)$ & $(+)$ & $(-)$ & $(-)$ \\
\hline 55 & 25 & 55 & $(+)^{\dagger}$ & $(+)^{\dagger}$ & $(+)$ & $(+)$ \\
\hline 94 & 20 & 79 & $(-)$ & $(+)$ & $(-)$ & $(+)$ \\
\hline 85 & 35 & 59 & $(+)$ & $(+)$ & $(-)$ & $(+)$ \\
\hline 82 & 44 & 46 & $(+)$ & $(+)$ & $(-)$ & $(+)$ \\
\hline 90 & 76 & 16 & $(+) \dagger$ & $(+) \dagger$ & $(+)$ & $(+)$ \\
\hline 74 & 65 & 12 & $(-)$ & $(-)$ & $(-)$ & $(-)$ \\
\hline 40 & 22 & 45 & $(-)$ & $(-)$ & $(-)$ & $(+)$ \\
\hline 60 & 28 & 53 & $(-)$ & $(-)$ & $(-)$ & $(+)$ \\
\hline 52 & 42 & 19 & $(-)$ & $(+)$ & $(-)$ & $(-)$ \\
\hline 68 & 28 & 59 & $(+)$ & $(+)$ & $(-)$ & $(-)$ \\
\hline $\begin{array}{l}70.1 \\
\pm \\
15.1\end{array}$ & $\begin{array}{l}39.8^{*} \\
\pm \\
16.1\end{array}$ & $\begin{array}{l}42.4 * * \\
\pm \\
19.6\end{array}$ & & & & \\
\hline
\end{tabular}


Table II. Effective Refractory Period (ERP)

Before LCX ligation

\begin{tabular}{|c|c|c|c|c|c|c|}
\hline \multirow{2}{*}{ Dog } & \multicolumn{2}{|c|}{ Normal zone } & \multicolumn{2}{|c|}{ Border zone } & \multicolumn{2}{|c|}{ Infarct zone } \\
\hline & $\begin{array}{c}\text { Range } \\
\text { (msec) }\end{array}$ & $\begin{array}{l}\Delta \mathrm{ERP} \\
\text { (msec) }\end{array}$ & $\begin{array}{l}\text { Range } \\
\text { (msec) }\end{array}$ & $\begin{array}{l}\triangle \mathrm{ERP} \\
\text { (msec) }\end{array}$ & $\begin{array}{l}\text { Range } \\
\text { (msec) }\end{array}$ & $\begin{array}{c}\text { JERP } \\
(\mathrm{msec})\end{array}$ \\
\hline 1 & $165-170$ & 5 & $175-180$ & 5 & $165-175$ & 10 \\
\hline 2 & 145 & 0 & $135-145$ & 10 & $140-150$ & 10 \\
\hline 3 & $150-155$ & 5 & $150-175$ & 25 & $155-180$ & 25 \\
\hline 4 & $140-145$ & 5 & $125-155$ & 30 & $155-175$ & 20 \\
\hline 5 & 165 & 0 & $145-160$ & 15 & $150-165$ & 15 \\
\hline 6 & 185 & 0 & $190-200$ & 10 & $185-200$ & 15 \\
\hline 7 & $170-180$ & 10 & $140 \div 165$ & 25 & $150-180$ & 30 \\
\hline 8 & 150 & 0 & $140-160$ & 20 & $130-160$ & 30 \\
\hline 9 & 145 & 0 & $125-140$ & 15 & $130-150$ & 20 \\
\hline 10 & $150-160$ & 10 & $135-155$ & 20 & $155-165$ & 10 \\
\hline 11 & 165 & 0 & $150-170$ & 20 & $150-165$ & 15 \\
\hline 12 & $155-160$ & 5 & $135-170$ & 35 & $145-170$ & 25 \\
\hline 13 & $140-150$ & 10 & $130-150$ & 20 & $125-145$ & 20 \\
\hline $\begin{array}{l}\text { mean } \\
\stackrel{+}{S E M}\end{array}$ & & $\begin{array}{l}3.9 \\
\pm \\
4.0\end{array}$ & & $\begin{array}{c}19.2^{*} \\
\pm \\
8.0\end{array}$ & & $\begin{array}{c}18.5^{*} \\
\pm \\
6.9\end{array}$ \\
\hline
\end{tabular}

After LCX ligation

\begin{tabular}{|c|c|c|c|c|c|c|}
\hline \multirow{2}{*}{ Dog } & \multicolumn{2}{|c|}{ Normal zone } & \multicolumn{2}{|c|}{ Border zone } & \multicolumn{2}{|c|}{ Infaret zone } \\
\hline & $\begin{array}{l}\text { Range } \\
\text { (msec) }\end{array}$ & $\begin{array}{l}\text { JERP } \\
\text { (msec) }\end{array}$ & $\begin{array}{l}\text { Range } \\
\text { (msec) }\end{array}$ & $\begin{array}{l}\Delta \mathrm{ERP} \\
(\mathrm{msec})\end{array}$ & $\begin{array}{c}\text { Range } \\
\text { (msec) }\end{array}$ & $\begin{array}{l}\triangle \mathrm{ERP} \\
\text { (msec) }\end{array}$ \\
\hline 1 & $165-170$ & 5 & $155-165$ & 10 & $160-180$ & 20 \\
\hline 2 & 145 & 0 & 135145 & 10 & $140-150$ & 10 \\
\hline 3 & $155-160$ & 5 & $150-185$ & 35 & $160-195$ & 35 \\
\hline 4 & $155-160$ & 5 & $145-185$ & 45 & $160-210$ & 50 \\
\hline 5 & 160 & 0 & $145-195$ & 50 & $145-165$ & 20 \\
\hline 6 & $180-185$ & 5 & $200-210$ & 10 & $195-220$ & 25 \\
\hline 7 & $170-180$ & 10 & $120-180$ & 60 & $150-170$ & 20 \\
\hline 8 & 160 & 0 & $160-210$ & 50 & $160-210$ & 50 \\
\hline 9 & $150-155$ & 5 & $135-160$ & 25 & $145-155$ & 10 \\
\hline 10 & $165-170$ & 5 & $165-175$ & 10 & $155-170$ & 15 \\
\hline 11 & $160-165$ & 5 & $165-190$ & 25 & $170-235$ & 65 \\
\hline 12 & $155-165$ & 10 & $160-175$ & 15 & $175-190$ & 15 \\
\hline 13 & $130-135$ & 5 & $155-165$ & 10 & $135-175$ & 40 \\
\hline $\begin{array}{c}\text { mean } \\
\pm \\
\mathrm{SEM}\end{array}$ & & $\begin{array}{l}4.6 \\
\pm \\
3.1\end{array}$ & & $\begin{array}{c}27.3^{*} \\
\pm \\
17.8\end{array}$ & & $\begin{array}{c}28.8^{*} \\
\pm^{* *} \\
16.9\end{array}$ \\
\hline
\end{tabular}

$* \mathrm{p}<0.01$ vs. normal zone, ** $\mathrm{p}<0.05$ vs. before LCX ligation. 
Table III. Local Intraventricular Conduction Time (LIVCT)

\begin{tabular}{|c|c|c|c|c|c|c|c|c|c|}
\hline \multirow{2}{*}{ Dog } & \multicolumn{3}{|c|}{ Normal zone } & \multicolumn{3}{|c|}{ Border zone } & \multicolumn{3}{|c|}{ Infarct zone } \\
\hline & $\underset{(\text { msec) }}{\text { B }}$ & $\underset{(\mathrm{msec})}{\mathrm{A}}$ & $\begin{array}{c}\Delta \mathrm{LIVCT} \\
\text { (msec) }\end{array}$ & $\begin{array}{c}\text { B } \\
(\mathrm{msec})\end{array}$ & $\begin{array}{c}A \\
(\mathrm{msec})\end{array}$ & $\begin{array}{c}\text { ALIVCT } \\
\text { (msec) }\end{array}$ & $\begin{array}{c}\mathrm{B} \\
(\mathrm{msec})\end{array}$ & $\begin{array}{c}\mathrm{A} \\
(\mathrm{msec})\end{array}$ & $\begin{array}{c}\Delta \mathrm{LIVCT} \\
\text { (msec) }\end{array}$ \\
\hline 1 & 30 & 32 & 2 & 32 & 36 & 4 & 34 & 48 & 14 \\
\hline 2 & 30 & 30 & 0 & 32 & 34 & 2 & 28 & 34 & 6 \\
\hline 3 & 16 & 18 & 2 & 20 & 30 & 10 & 26 & 28 & 2 \\
\hline 4 & 14 & 14 & 0 & 24 & 36 & 12 & 32 & 36 & 4 \\
\hline 5 & 22 & 24 & 2 & 30 & 34 & 4 & 26 & 40 & 14 \\
\hline 6 & 24 & 26 & 2 & 32 & 46 & 14 & 32 & 36 & 4 \\
\hline 7 & 30 & 32 & 2 & 36 & 48 & 12 & 34 & 42 & 8 \\
\hline 8 & 20 & 22 & 2 & 34 & 44 & 10 & 36 & 38 & 2 \\
\hline 9 & 22 & 22 & 0 & 20 & 24 & 4 & 28 & 34 & 6 \\
\hline 10 & 16 & 18 & 2 & 22 & 32 & 10 & 20 & 26 & 6 \\
\hline 11 & 18 & 18 & 0 & 24 & 26 & 2 & 32 & 36 & 4 \\
\hline 12 & 30 & 32 & 2 & 38 & 48 & 10 & 34 & 36 & 2 \\
\hline 13 & 20 & 22 & 2 & 36 & 50 & 14 & 30 & 42 & 10 \\
\hline $\begin{array}{l}\text { mean } \\
\stackrel{ \pm}{\mathrm{SEM}}\end{array}$ & $\begin{array}{c}22.5 \\
\pm \\
5.7\end{array}$ & $\begin{array}{c}23.8 \\
\pm \\
5.9\end{array}$ & $\begin{array}{l}1.4 \\
\pm \\
0.9\end{array}$ & $\begin{array}{l}29.2 \\
\pm \\
6.2\end{array}$ & $\begin{array}{c}37.5^{*} \\
\pm \\
8.7\end{array}$ & $\begin{array}{l}8.3^{* *} \\
\pm \\
4.3\end{array}$ & $\begin{array}{c}30.2 \\
\pm \\
4.3\end{array}$ & $\begin{array}{c}36.6 * \\
\pm \\
5.7\end{array}$ & $\begin{array}{l}6.3^{* *} \\
\pm \\
4.0\end{array}$ \\
\hline
\end{tabular}

B, before LCX ligation, A, after LCX ligation.

JLIVGT $=$ difference between $\mathrm{B}$ and $\mathrm{A},{ }^{*} \mathrm{p}<0.01$ vs. $\mathrm{B}$ in each zone, $* * \mathrm{p}<0.01$ vs. normal zone.

tion. The $\triangle \mathrm{ERP}$ in the border and the infarct zones increased to a variable extent after LCX ligation. The $\triangle E R P$ was $28.8 \pm 16.9 \mathrm{msec}$, with a range of 10 to $65 \mathrm{msec}$, in the infarct zone and $27.3 \pm 17.8 \mathrm{msec}$, with a range of 10 to $60 \mathrm{msec}$, in the border zone. These marked increases in $\triangle \mathrm{ERP}$ of the border and the infarct zones were observed particularly in the dogs with electrically induced ventricular fibrillation.

Table III shows the results of the local intraventricular conduction time (LIVCT) study. Before LCX ligation, the LIVCT was $22.5 \pm 5.7 \mathrm{msec}$ with a range of 14 to $30 \mathrm{msec}$ in the normal zone, $29.2 \pm 6.2 \mathrm{msec}$ with a range of 20 to $38 \mathrm{msec}$ in the border zone and $30.2 \pm 4.3 \mathrm{msec}$ with a range of 20 to $36 \mathrm{msec}$ in the infarct zone. After LCX ligation, the LIVCT increased significantly by $8.3 \pm 4.3 \mathrm{msec}$ to $37.5 \pm 8.7 \mathrm{msec}$ in the border zone and by $6.3 \pm$ $4.0 \mathrm{msec}$ to $36.6 \pm 5.7 \mathrm{msec}$ in the infarct zone; whereas no significant change was observed in the normal zone. Increases in LIVCT in the border and the infarct zones were more prominent in the dogs with electrically induced ventricular tachycardia and/or fibrillation.

The regional myocardial blood flow (RMBF) measurements from 3 zones of the left ventricle are listed in Table I. Before LCX ligation, the RMBF 

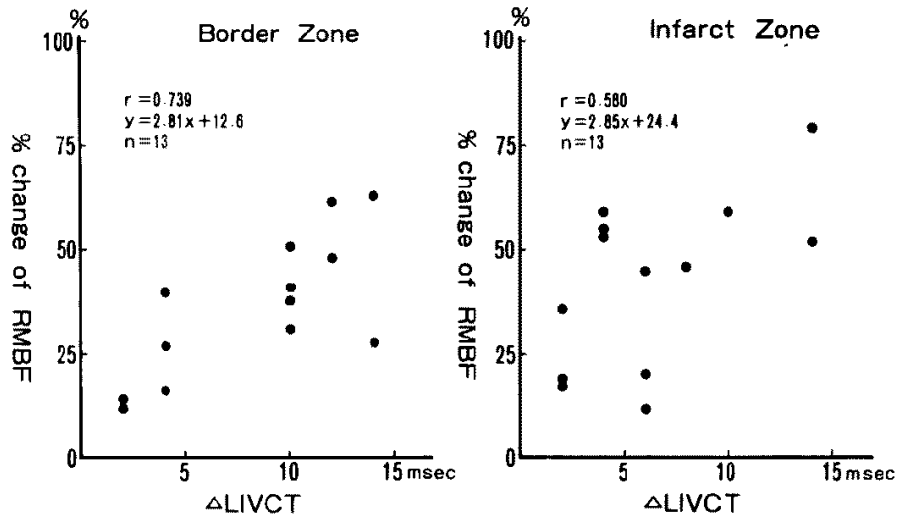

Fig. 3. Relationship between the change in local intraventricular conduction time (LIVCT) and the percent change of regional myocardial blood flow (RMBF) after ligation of the left circumflex coronary artery (LCX) in the border and the infarct zones of the left ventricle. A significant correlation was observed.
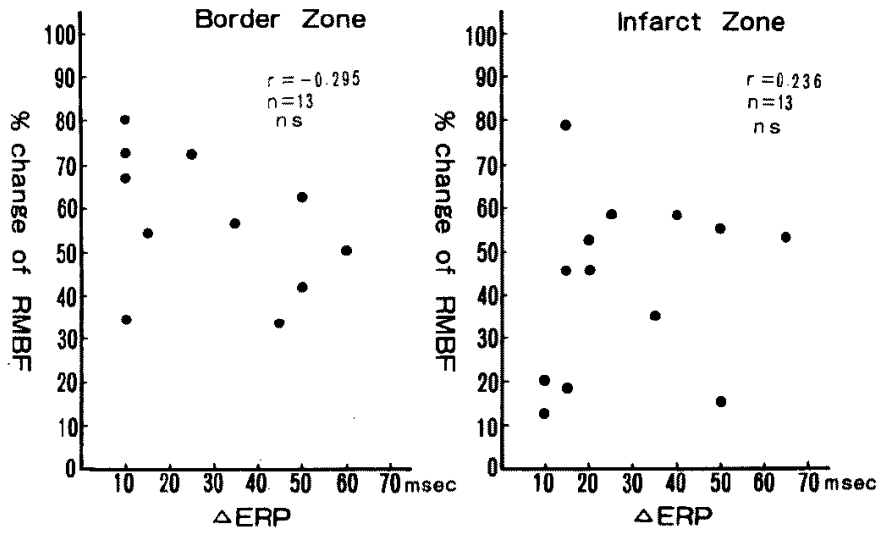

Fig. 4. Relationship between heterogeneity of the effective refractory period (ERP) and the percent change of regional myocardial blood flow (RMBF), after ligation of the left circumflex coronary artery (LCX), in the border and the infarct zones of the left ventricle. There was no significant correlation between them in either zone.

was $148.3 \pm 18.2 \mathrm{ml} / \mathrm{min} / 100 \mathrm{~g}$ in the normal zone, $88.2 \pm 9.8 \mathrm{ml} / \mathrm{min} / 100 \mathrm{~g}$ in the border zone and $70.1 \pm 15.1 \mathrm{ml} / \mathrm{min} / 100 \mathrm{~g}$ in the infarct zone. After LCX ligation, RMBF decreased significantly and reached $51.2 \pm 15.5 \mathrm{ml} / \mathrm{min} / 100 \mathrm{~g}$ in the border zone and $39.8 \pm 16.1 \mathrm{ml} / \mathrm{min} / 100 \mathrm{~g}$ in the infarct zone; no significant change in $\mathrm{RMBF}$ was observed in the normal zone. The percent change of RMBF was $36.0 \pm 16.3 \%$, with a range of 11 to $63 \%$ in the border zone and $42.4 \pm 19.6 \%$, with a range of 12 to $79 \%$ in the infarct zone. In 
the 11 dogs with electrically induced ventricular arrhythmias, the percent change in RMBF after LCX ligation was $40.1 \pm 14.3 \%$ in the border zone and $47.2 \pm 17.3 \%$ in the infarct zone. By contrast, the percent change in RMBF in 2 dogs without electrically induced ventricular arrhythmias was small $(13.5 \pm 2.5 \%$ in the border zone and $16.0 \pm 4.0 \%$ in the infarct zone). There was a significant correlation between the percent change of RMBF and $\Delta$ LIVCT in the border and the infarct zones (Fig. 3), but there was no consistent correlation between percent change of RMBF and $\triangle \mathrm{ERP}$ in the border and the infarct zones (Fig. 4).

\section{Discussion}

Hydrogen clearance method for determination of regional myocardial blood flow (RMBF) was first used by Auckland. ${ }^{7}$ It has been reported that the RMBF obtained by hydrogen clearance method correlates highly radioactive microsphere determinations. ${ }^{81}$ We used stochastic analysis (Height-Area Method) on the basis of Zierler's theory ${ }^{6)}$ in the present study. The hydrogen clearance method has several advantages. First, it gives the absolute value of myocardial blood flow. Second, it can be repeated every 15 to $20 \mathrm{~min}$. Third, blood sampling is not required and injury of measured tissue is minimum. Finally, simultaneous measurements at multiple sites are possible.

Kabell et $\mathrm{al}^{9)}$ reported that stenosis of the left circumflex coronary artery caused a decrease in blood flow to the subepicardium of the infarct zone in dogs with 4 day old anterior wall infarction produced by complete occlusion of the LAD. However, there was no significant change in subendocardial blood flow. ${ }^{3}$ In the present study, the RMBF obtained from the endocardial side of the left ventricle was consistently smaller in the border and the infarct zones than in the normal zone; it decreased further after LCX ligation. This marked reduction of subendocardial blood flow in the border and the infarct zones differs from the results of the study of Kabell et al.9) This difference may be due in part to the difference in the post infarction period which was 28 days in our study in comparison to 4 days in the study of Kabell et al. It has been shown that collateral blood flow in the ischemic region following coronary occlusion increases with time. ${ }^{11,12)}$ It is, therefore, assumed that the reduction of $\mathrm{RMBF}$ in the border and the infarct zones is more profound in the chronic phase than in the early phase of myocardial infarction. These reductions of RMBF in the border and the infarct zones after LCX ligation in the present study imply that the LCX is an important source of collateral blood supply to the border and the infarct zones of the left ventricle. 
Myerburg et al ${ }^{3)}$ reported a high incidence of spontaneous and induced ventricular tachycardias when acute ischemia coexisted with old ischemic injury in cats. Schwartz et $\mathrm{al}^{4 /}$ also reported a $65 \%$ incidence of ventricular fibrillation within 10 min of LCX occlusion imposed one month after experimental myocardial infarction. Recently, Patterson et al ${ }^{5)}$ demonstrated that the incidence of ventricular fibrillation was $97 \%$ when the thrombosis of LCX was induced by electrical intimal injury 4 days following anterior wall infarction in conscious dog. In the present study, the incidence of electrically induced ventricular arrhythmias increased significantly $(\mathrm{p}<0.05)$ from $46 \%$ to $85 \%$ after LCX ligation. This finding is consistent with previous studies suggesting that a combination of acute ischemia and preexisting ischemic injury has a highly arrhythmogenic potential. It has been reported that a reduction of blood flow by $90 \%$ or more is required for the occurrence of ventricular arrhythmias in acute myocardial ischemia. ${ }^{101}$ In the present study, though, a lesser degree of blood flow reduction in the border and the infarct zones resulted in a high incidence of electrically induced ventricular arrhythmias when acute ischemia was superimposed on healed myocardial infarction. The greatest percent RMBF changes were 31 to $79 \%$ in dogs with electrically induced ventricular tachycardia and/or fibrillation $(\mathbf{n}=11)$ and 45 to $79 \%$ in dogs with electrically induced ventricular fibrillation $(n=7)$.

Myerburg et $\mathbf{a l}^{3)}$ demonstrated that coexistence of acute ischemia and a healed myocardial infarction resulted in wide variability in action potential durations of myocardial cells, resulting in heterogeneity in the local refractory period. Recently, Patterson et $a^{5}$ reported that ventricular fibrillation was preceded by the development of delayed electrical activity when a circumflex coronary artery thrombosis was produced by electrical intimal injury 4 days following occlusion of the left anterior descending coronary artery in conscious dogs. However, they did not examine the relationship between changes in electrophysiologic properties of the left ventricle and the magnitude of reduction of collateral blood supply to the preexisting ischemic area. In the present study, heterogeneity of the effective refractory period and the local intraventricular conduction time in the border and the infarct zones of the left ventricle were increased by LCX ligation in dogs with a healed myocardial infarction. The LIVCT had a positive correlation with the magnitude of reduction of $\mathrm{RMBF}$ in the border and the infarct zones of the left ventricle, but there was no significant correlation between the heterogeneity of effective refractory period and the magnitude of the reduction of RMBF. Despite a lack of a statistically significant correlation, the heterogeneity of the effective refractory period increased to various extents in association with reduction of $\mathrm{RMBF}$. 


\section{ACKNoWLedgMents}

This study was performed at the Laboratory Animal Center for Biomedical Research, Nagasaki University School of Medicinc. The technical assistance of Mr. Kunihiko Kawao is gratefully acknowledged. The authors would like to thank Miss Yukiko Fukui for her expert secretarial assistance in the preparation of the manuscript.

\section{References}

1. Schaffer WA, Cobb LA: Recurrent ventricular fibrillation and mode of death in survivors of out-of-hospital ventricular fibrillation. New Engl J Med 293: 259, 1975

2. Liberthson RR, Nagel EL, Hirshman JC, Nussenfeld SR: Pre-hospital ventricular fibrillation: Prognosis and follow-up course. New Engl J Med 291: 317, 1974

3. Myerburg RJ, Basset AL, Nilsson K, Castellanos A, Sung RJ, Gelband H: Electrophysiologic interactions between acute ischemia and healed experimental myocardial infarction cats. Am J Cardiol 41: 365, 1978

4. Schwartz PJ, Stone HL: Left stellectomy in the prevention of ventricular fibrillation caused by acute myocardial ischemia in conscious dogs with anterior myocardial infarction. Circulation 62: 1256, 1980

5. Patterson E, Holland K, Eller BT, Lucchesi BR: Ventricular fibrillation resulting from ischemia at a site remote from previous myocardial infarction. Am J Cardiol 50: 1414, 1982

6. Zierler KL: Equations for measuring blood flow by external monitoring of radioisotopes. Circ Res 16: 164, 1965

7. Auckland K, Bower BF, Berliner RW: Measurement of local blood flow with hydrogen gas. Circ Res 14: 164, 1964

8. Kinoshita M, Katayama Y, Kawakita S: Measurement of regional myocardial blood flow with hydrogen clearance method. J Jap Coll Angiol 21: 183, 1981 (in Japanese)

9. Kabell G, Brachmann J, Scherlag BJ, Harrison L, Lazzara R: Mechanism of ventricular arrhythmias in multivessel coronary disease: The effects of collateral zone ischemia. Am Heart J 108: 447, 1984

10. Kabell G, Scherlag BJ, Guse P, Hope RR, Lazzara R: Ventricular arrhythmias and regional myocardial blood flow in acute and subacute myocardial infarction: Effects of the carboxylic ionophore monensin. J Cardiovasc Pharmacol 3: 61, 1981

11. Marcus ML, Kerver RE, Ehrhardt J, Abbound FM: Effects of time on volume and distribution of coronary collateral flow. Am J Physiol 230: 279, 1976

12. Rivas F, Cobb FR, Bache RJ, Greenfield JC Jr: Relationship between blood flow to ischemic regions and extent of infarction. Circ Res 38: 439, 1976 